\title{
Optimization of culture conditions for antimetabolite production by a rare tea garden actinobacterial isolate, Amycolatopsis Sp. ST-28
}

\author{
Alam, M., and *Jha, D. K. \\ Microbial Ecology Laboratory, Department of Botany, \\ Gauhati University, Guwahati-781014, Assam, India \\ *Correspondence to: dkjhabot07@gmail.com
}

\begin{abstract}
:
Background: Microbial metabolites are of great importance to the pharmaceutical industries. There is an urgent need of novel microbial metabolites in the present scenario to combat antimicrobial resistance. Selection and screening of potent microbial strains for production of antimicrobial metabolites as well as optimization of their culture conditions is of utmost importance in drug discovery. Therefore, the study was carried out to evaluate the effect of nutritional and cultural conditions on the production of bioactive metabolites by a rare tea garden actinobacterial strain Amycolatopsis sp. ST-28.

Materials and methods: Submerged fermentation of the actinobacterial isolate was carried out on different culture media and different culture conditions such as carbon and nitrogen sources, inoculum volume, $\mathrm{pH}$, fermentation period and agitation speed. The culture filtrate was assayed against Staphylococcus aureus. Agar well diffusion method was employed to determine the maximum diameter of zone of inhibition $(\mathrm{mm})$. The dried mycelial weight $(\mathrm{mg})$ in a fixed volume of culture media was used for the determination of the total biomass produced.

Results: Maximum bioactive metabolite and biomass production was observed when submerged fermentation was carried out with mannose and peptone respectively as a sole carbon and nitrogen source. Maintaining other environmental parameters viz. inoculum $11 \%(\mathrm{v} / \mathrm{v}), \mathrm{pH}$ of 6.5 , temperature of $32^{\circ} \mathrm{C}$ and incubation period of 11 days at $150 \mathrm{rpm}$ were found optimum for maximum antimicrobial activity.
\end{abstract}

Conclusion: This study demonstrated optimized cultural conditions for improved production of antimicrobial compound by Amycolatopsis sp. ST-28

Keywords: Amycolatopsis, antimicrobial, submerged fermentation, optimization.

Received April 2, 2019; Revised April 15, 2019; Accepted April 16, 2019

Copyright 2019 AJCEM Open Access. This article is licensed and distributed under the terms of the Creative Commons Attrition 4.0 International License (http://creativecommmons.org/licenses/by/4.0), which permits unrestricted use, distribution and reproduction in any medium, provided credit is given to the original author(s) and the source.

\section{Optimisation des conditions de culture pour la production d'antimétabolites par un isolat rare d'actinobactéries de jardin de thé, Amycolatopsis sp. ST-28}

Laboratoire d'écologie microbienne, Département de botanique, Université Gauhati, Guwahati-781014, Assam, Inde

* Correspondance à: dkjhabot07@gmail.com 


\begin{abstract}
Abstrait:
Contexte: Les métabolites microbiens revêtent une grande importance pour les industries pharmaceutiques. Il existe un besoin urgent de nouveaux métabolites microbiens dans le scénario actuel pour lutter contre la résistance aux antimicrobiens. La sélection et le criblage de souches microbiennes puissantes pour la production de métabolites antimicrobiens, ainsi que l'optimisation de leurs conditions de culture, revêtent une importance capitale pour la découverte de médicaments. Par conséquent, l'étude a été réalisée pour évaluer l'effet des conditions nutritionnelles et culturelles sur la production de métabolites bioactifs par une rare souche d'actinobactéries de jardin de thé, Amycolatopsis sp. ST-28.

Matériels et méthodes: La fermentation immergée de l'isolat actinobactérien a été réalisée sur différents milieux de culture et différentes conditions de culture tels que les sources de carbone et d'azote, le volume d'inoculum, le $\mathrm{pH}$, la période de fermentation et la vitesse d'agitation. Le filtrat de culture a été testé contre Staphylococcus aureus. La méthode de diffusion sur puits d'agar a été utilisée pour déterminer le diamètre maximum de la zone d'inhibition $(\mathrm{mm})$. Le poids du mycélium séché $(\mathrm{mg})$ dans un volume fixe de milieu de culture a été utilisé pour la détermination de la biomasse totale produite.

Résultats: Une production maximale de métabolites bioactifs et de biomasse a été observée lors de la fermentation en immersion avec du mannose et de la peptone, respectivement, comme seule source de carbone et d'azote. Maintenir d'autres paramètres environnementaux à savoir. inoculum $11 \%(\mathrm{v} /$ v), $\mathrm{pH}$ de 6,5 , température de $32^{\circ} \mathrm{C}$ et période d'incubation de 11 jours à $150 \mathrm{tr} / \mathrm{min}$ ont été jugés optimaux pour une activité antimicrobienne maximale.

Conclusion: Cette étude a démontré des conditions de culture optimisées pour une production améliorée de composé antimicrobien par Amycolatopsis sp. ST-28
\end{abstract}

Mots clés: Amycolatopsis, antimicrobien, fermentation en immersion, optimisation

\section{Introduction:}

Natural products with industrial applications are produced by the metabolism of living organisms (plants, animals or microorganisms). The most economical natural compounds produced by microorganisms, other than enzymes and recombinant proteins, are the low molecular weight primary and secondary metabolites (1). One microbe usually produces more than one compound, for example, a gentamicin-producing strain of Micromonospora produces 50 isolatable secondary metabolites (2).

Microbes isolated from nature usually produce extremely low levels of such metabolites. In order for a natural product to become a commercial reality, overproduction must be achieved initially at the laboratory level. Screening of proper strain and knowledge of microbial physiology is crucial to achieving higher metabolite production. The nutrition, growth and death rates, transport, energy, building blocks, polymer synthesis, regulation of enzyme synthesis, action and degradation, as well as cellular differentiation are some of the factors influencing natural metabolite production.

Production of antibiotics by microorganisms differs qualitatively and quantitatively depending on the strains and species of microorganisms used as well as on their nutritional and cultural conditions (3). Changes in the culture medium and the sole source of carbon and nitrogen have great influence on the growth and antibiotic production by microorganisms as reported by different researchers $(4,5,6)$. Thus, a mastery of the fermentation process for each new strain, sound engineering knowledge of media optimization, and the fine-tuning of process conditions are required to yield integrated and successful processes (7).

Microbial products have so long been exploited for their richness in the medical field. There has been tremendous progress made and success recorded in the field of antibiotic since the discovery of penicillin. However, the war against infectious diseases is yet to be won because of ever increasing threats of antimicrobial resistance of the microorganisms. One of such threats is 
Staphylococcus aureus, an important pathogen of public health concern that has evolved into multiple antimicrobial resistant strains now considered a major problem. The organism can cause a wide variety of diseases ranging from superficial infections to severe lifethreatening diseases such as pneumonia, endocarditis, septicaemia, and variety of toxin-mediated diseases including staphylococcal scalded-skin syndrome and toxic shock syndrome $(8,9,10)$.

The search for new antibiotics should therefore be continued in order to overcome resistance of microorganisms. In this respect, efforts are being made to exploit the chemical diversity of the rare actinobacteria isolated from unexplored habitats, which may increase the chances of discovering novel structures of biotechnological importance (11). One such possible candidate of this rare actinobacterial group is the genus Amycolatopsis, proposed by Lechevalier et al., in 1986 on the basis of 16S rRNA gene sequence analysis (12). Amycolatopsis belongs to family Pseudonocardiaceae $(13,14)$ which are Gram positive, non acid fast, non motile, catalase positive actinobacteria. There has been intense scientific interest and focus on this genus due to its ability to produce diverse group of antibiotics and secondary metabolites. Some important antibiotics such as balhimycin, dethymicin, rifamycin and vancomycin are produced by Amycolatopsis strains. There is therefore the need to conduct more elaborate studies on this prolific group of rare actinobacteria for better understanding of its hidden potential and diversity (15-18).

Northeast India has been identified as the Indo-Burma hotspot due to its rich variation in the flora and fauna (19). However, information about the microbial diversity of this region is sparse in the literature. Owing to its pristine location, it is a treasure house of diverse microorganisms and novel metabolites that is waiting to be discovered for medical use. In our course of investigation for novel microbial metabolites that have both pharmaceutical and agricultural importance, Amycolatopsis sp. ST-28, a tea garden isolate was screened against Staphylococcus aureus. In this study, attempt was made to determine the influence of different culture media, various carbon and nitrogen sources, inoculum volume, temperature, $\mathrm{pH}$, aeration, and incubation period on invitro optimum growth and bioactive metabolite production by Amycolatopsis sp. ST-28.

\section{Materials and methods:}

\section{Microbial strains}

Amycolatopsis sp. ST-28 was isolated using various selective isolation procedures $(20,21)$ from tea garden soil in Golaghat district, Assam, India (N 26027.534', E 093055.859'). Identification and characterization of the actinobacterial strain was done on the basis of colony morphology, biochemical and physiological properties $(22,23)$. The identity of the isolate was confirmed by PCR based 16S rRNA gene sequence analysis and the isolate has been deposited in GenBank with accession number (KY111723) (24). The strain was maintained in ISP-2 medium (yeast and malt extract medium) composed of yeast extract $4.0 \mathrm{~g}$, malt extract $10 \mathrm{~g}$, dextrose $4 \mathrm{~g}$, agar $15 \mathrm{~g}$ and $\mathrm{pH}$ 7.3. The test organism, Staphylococcus aureus MTCC737 was collected from the Institute of Microbial Technology (IMTECH), Chandigarh, India. The organism was maintained on Mueller Hinton agar (HiMedia, India) and preserved at $4{ }^{\circ} \mathrm{C}$ for two months and in deep freezer at $-70^{\circ} \mathrm{C}$ in $15 \%(\mathrm{v} / \mathrm{v})$ glycerol for longer period (25).

\section{Submerged fermentation}

\section{Inoculum preparation}

Two different media were used for production of inoculum with the following composition ( $\mathrm{g} / \mathrm{L}$ ) (26); (i) IM-1 (Organic medium) composed of beef extract $3.0 \mathrm{~g}$, tryptone $5.0 \mathrm{~g}$, dextrose $1.0 \mathrm{~g}$, potato starch $24.0 \mathrm{~g}, \mathrm{CaCO}_{3} 2.0 \mathrm{~g}$, and (ii) $\mathrm{IM}-2$ (Complex medium) composed of soyabean meal $10.0 \mathrm{~g}$, corn steep solid $10.0 \mathrm{~g}$, 
glucose $5.0 \mathrm{~g}$ and $\mathrm{CaCO}_{3} 5.0 \mathrm{~g}$. The colonies from the previously grown pure culture of Amycolatopsis sp. ST-28 in ISP-2 medium was scrapped with $5 \mathrm{ml}$ of distilled water to make a colony suspension (26). This was then transferred to $45 \mathrm{ml}$ of each medium contained in $250 \mathrm{ml}$ capacity conical flasks which were incubated on a rotary shaking incubator at $28 \pm 1^{\circ} \mathrm{C}$ and $220 \mathrm{rpm}$ for 48 hours. A $10 \%$ $(\mathrm{v} / \mathrm{v})$ inoculum was transferred to a production medium (composed of sucrose $2.0 \mathrm{~g}$, malt extract $10 \mathrm{~g}$, yeast extract $4.0 \mathrm{~g}$, dipotassium hydrogen phosphate $5.0 \mathrm{~g}$, sodium chloride $2.5 \mathrm{~g}$, zinc sulphate $0.04 \mathrm{~g}$, calcium carbonate $0.4 \mathrm{~g}, 1.0 \mathrm{~L}$ distilled water, and $\mathrm{pH}$ 7.0). The fermentation was run at $30^{\circ} \mathrm{C}$ for 5 days on a rotary shaker at $220 \mathrm{rpm}$. The growth and antimicrobial activity were determined at the end of incubation period, and the best inoculum medium was used for optimization studies (26).

\section{Basal media preparation}

Seven fermentation media

(HiMedia Laboratories, Mumbai, India) were inoculated with the Amycolatopsis sp. ST-28 strain for the production of antimicrobial secondary metabolites containing the following compositions $(\mathrm{g} / \mathrm{L})$ at $\mathrm{pH}$ of 7 ; (i) Starch casein medium (SCM) with soluble starch $10.0 \mathrm{~g}$, casein $1.0 \mathrm{~g}, \mathrm{CaCO}_{3} .2 \mathrm{H}_{2} \mathrm{O} 10.0 \mathrm{~g}$ and $\mathrm{K}_{2} \mathrm{HPO}_{4} 0.5 \mathrm{~g}$ (22); (ii) Bennett's medium (BM) with Dglucose $10.0 \mathrm{~g}$, beef extract $1.0 \mathrm{~g}$, yeast extract $1.0 \mathrm{~g}$ and $\mathrm{N}-\mathrm{Z}$ amine type $\mathrm{A}$ (casein hydrolysate) $2.0 \mathrm{~g} \mathrm{(27);} \mathrm{(iii)} \mathrm{Soyabean}$ medium (SM) with Dextrin $15.0 \mathrm{~g}$, soyabean $30.0 \mathrm{~g}, \mathrm{CaCO} 3.2 \mathrm{H}_{2} \mathrm{O} 10.0 \mathrm{~g}$ and $\mathrm{MgSO}_{4} \cdot 7 \mathrm{H}_{2} \mathrm{O} 1.0 \mathrm{~g}$ (28); (iv) $\mathrm{C}$ medium (CM) with D-glucose $10.0 \mathrm{~g}$, soluble starch $35.0 \mathrm{~g}$, casein hydolysates $5.0 \mathrm{~g}$, yeast extract $8.0 \mathrm{~g}$, meat extract $3.5 \mathrm{~g}$, soyabean meal $3.5 \mathrm{~g}$ and $\mathrm{CaCO}_{3} .2 \mathrm{H}_{2} \mathrm{O} 2.0 \mathrm{~g}(29)$; (v) ISP-2 medium with glucose $4.0 \mathrm{~g}$, malt extract $10.0 \mathrm{~g}$ and yeast extract $4.0 \mathrm{~g}(30)$; (vi) ISP-4 medium with soluble starch $10.0 \mathrm{~g}, \mathrm{~K}_{2} \mathrm{HPO}_{4} 1.0 \mathrm{~g}, \mathrm{MGSO}_{4} .7 \mathrm{H}_{2} \mathrm{O} 1.0 \mathrm{~g}$ ， $\mathrm{NaCl} 1.0,\left(\mathrm{NH}_{4}\right) 2 \mathrm{SO}_{4} 2.0 \mathrm{~g}, \mathrm{CaCO}_{3} 2.0 \mathrm{~g}$ (22); and (vii) Glycerol asparagine medium (GAM) with L-asparagine $1.0 \mathrm{~g}$, glycerol $10.0 \mathrm{~g}, \mathrm{~K}_{2} \mathrm{HPO}_{4} 1.0 \mathrm{~g}$, and trace salt solution $1.0 \mathrm{ml}(22)$.

The colony suspension of Amycolatopsis sp. ST-28 was prepared as described earlier. A $10 \%(\mathrm{v} / \mathrm{v})$ inoculum was transferred to each of the above seven media and incubated at $30 \pm 1^{\circ} \mathrm{C}$ for 10 days on a rotary shaking incubator at 220rpm. Growth and antimicrobial activity were determined at the end of incubation period and the best medium was selected as the basal medium which also serves as control for further experiments.

\section{Invitro antibiosis and microbial growth}

The culture broth of Amycolatopsis sp. ST-28 was centrifuged and filter sterilized (with $0.4 \mu \mathrm{m}$ cellulose acetate). This was then bio-assayed against Staphylococcus aureus using agar well diffusion technique (31). Briefly, $0.1 \mathrm{ml}$ of test bacterial suspension containing $3 \times 10^{8}$ cells/ml was spread aseptically on Mueller Hinton agar and $50 \mu \mathrm{L}$ of culture broth was pipetted onto agar wells prepared by a sterile cork borer $(6.00 \mathrm{~mm}$ in diameter). The diameter of zone of inhibition was recorded after 24 hours of incubation at $30 \pm 2^{\circ} \mathrm{C}$. Growth was measured in terms of dry mycelial weight in a fixed volume $(50 \mathrm{ml})$ of culture medium after drying the cell in an oven at $70^{\circ} \mathrm{C}$ overnight (25).

\section{Optimization studies}

Optimization of antimicrobial metabolite production was carried out with the removal and supplementation of nutrients based on single-dimension optimization (32). To determine the ideal condition for growth and maximum bioactive metabolite production, starch casein medium (SCM) with or without carbon and nitrogen sources was selected as the basal medium. A $10 \%$ (v/v) inoculum was transferred to the basal medium of $50 \mathrm{ml}$. Flasks were incubated under stationary condition at $30 \pm 1^{\circ} \mathrm{C}$ for 10 days.

Various parameters influencing the growth and antimicrobial metabolite production viz effect of medium supplements such as carbon and nitrogen sources and effect of the physiological conditions such as $\mathrm{pH}$, temperature, 
incubation period, inoculum size and agitation were studied. The experiments were conducted in triplicates.

\section{Carbon and nitrogen supplement}

Lactose, glucose, mannose, glycerol, galactose, starch, mannitol, starch, ethanol, succinic acid and sucrose were used as carbon source, while sodium nitrate, potassium nitrate, ammonium sulphate, L-asparagine, peptone, beef extract, ammonium chloride, malt extract, yeast extract and L-tryptophan were used as nitrogen source. Each carbon and nitrogen source was incorporated separately at $1.0 \%(\mathrm{w} / \mathrm{v})$ level into the basal medium. The carbon sources were ether-sterilized to prevent denaturation (22).

\section{Effect of temperature, $\mathrm{pH}$, agitation, incubation period and inoculum volume}

The optimum temperature for antimicrobial metabolite production was determined using different incubation temperatures ranging from 20 to $45 \pm 1^{\circ} \mathrm{C}$ in accordance with the method described by Suetsuna and Osajima in 1990 (33). Different $\mathrm{pH}$ values ranging from 5 to 9 were used after adjusting $\mathrm{pH}$ level of the basal medium with $1 \mathrm{~N} \mathrm{HCl}$ or $\mathrm{NaOH}$. To determine the effect of aeration on growth and active metabolite production, culture flasks were incubated at $32 \pm 1^{\circ} \mathrm{C}$ in an orbital shaking incubator at $150 \mathrm{rpm}$ as well as at stationary phase. The effect of incubation period for maximum growth and antimicrobial metabolite production was observed up to 20 days of incubation. For all the previous experiments, 10\% $(v / v)$ fresh culture was used as inoculum but in the present experiment, varying inoculum volumes of 2 to $15 \%(\mathrm{v} / \mathrm{v})$ were evaluated. Fermentation was carried out and bioactive metabolite produced was assayed (26).

\section{Statistical analysis}

The mean and standard errors of mean $( \pm S E)$ were calculated for each experiment. Differences observed between various tested variables were determined using Analysis of Variance (ANOVA) and
Fisher's LSD was calculated with Statistical Package for the Social Sciences (SPSS) software version 18.0. Significance was considered where calculated $p$ value was less than 0.05 .

\section{Results:}

\section{Choice of target organism}

Amycolatopsis sp. ST-28 was assessed for its antimicrobial activity against Staphylococcus aureus and it showed prominent antimicrobial activity with zone of inhibition of $25 \pm 0.1 \mathrm{~mm}$, hence for the study, it was taken as the choice target organism for culture filtrate assay.

\section{Standardization of inoculum and basal media}

Two different media were tested for inoculum production, IM-1 and IM-2. IM-1 (Organic medium) produced growth with dry mycelial weight of $42 \pm 0.3$ $\mathrm{mg} / 250 \mathrm{ml}$ and antimicrobial activity with diameter of inhibition of $9 \pm 0.1 \mathrm{~mm}$ while IM-2 (Complex medium) produced growth with dry mycelial weight of $67 \pm 0.02$ $\mathrm{mg} / 250 \mathrm{ml}$ and antimicrobial activity with diameter of inhibition of $14 \pm 0.66 \mathrm{~mm}$. Therefore IM-2, which supported maximum yield in terms of growth and antimicrobial activity, was used for further experiment.

Amycolatopsis sp. ST-28 produced highest biomass $(65.33 \pm 1.2 \mathrm{mg})$ as well as bioactive metabolite with maximum zone of inhibition $(26.66 \pm 0.33 \mathrm{~mm})$ against Staphylococcus aureus, when grown on Starch Casein (SC) medium (Fig 1 ). The other six media also supported the growth of the strain however the bioactivity was less compared with SC medium. Therefore, SC medium with or without carbon and nitrogen sources was used as the basal medium (control) for rest of the experiments.

\section{Effect of carbon and nitrogen source}

All of the test carbon sources supported the growth of Amycolatopsis sp. ST-28 (Fig 2). Maximum growth and bioactive metabolite production were 
obtained in the basal medium supplemented with mannose as sole carbon source followed by basal medium with dextrose and glycerol (Fig 2). The result showed that mannose at a concentration of $1 \%(\mathrm{w} / \mathrm{v})$ produced maxi-

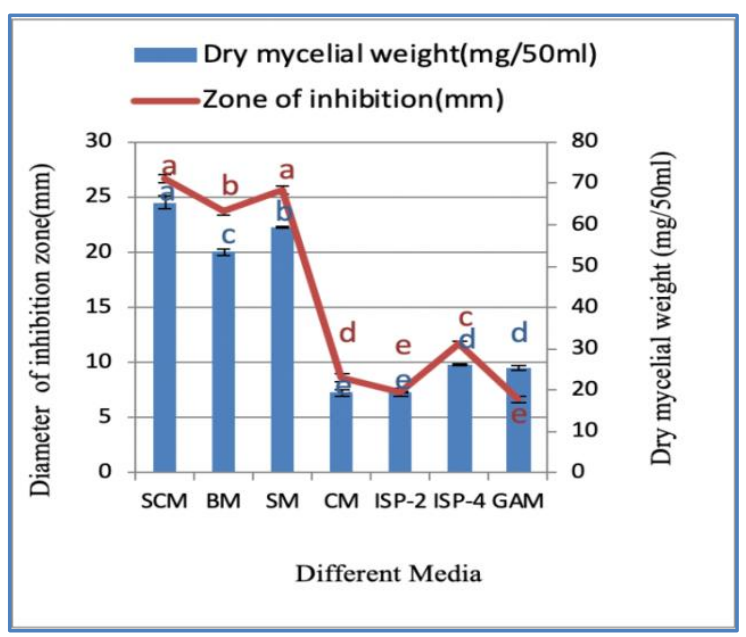

Fig 1: Effect of different culture media on growth and bioactive metabolite production by Amycolatopsis sp. ST-28. Vertical bars represent standard error ( \pm SE).

Means with different letters within an assay were significantly different ( $p$ value $<0.05$ ).

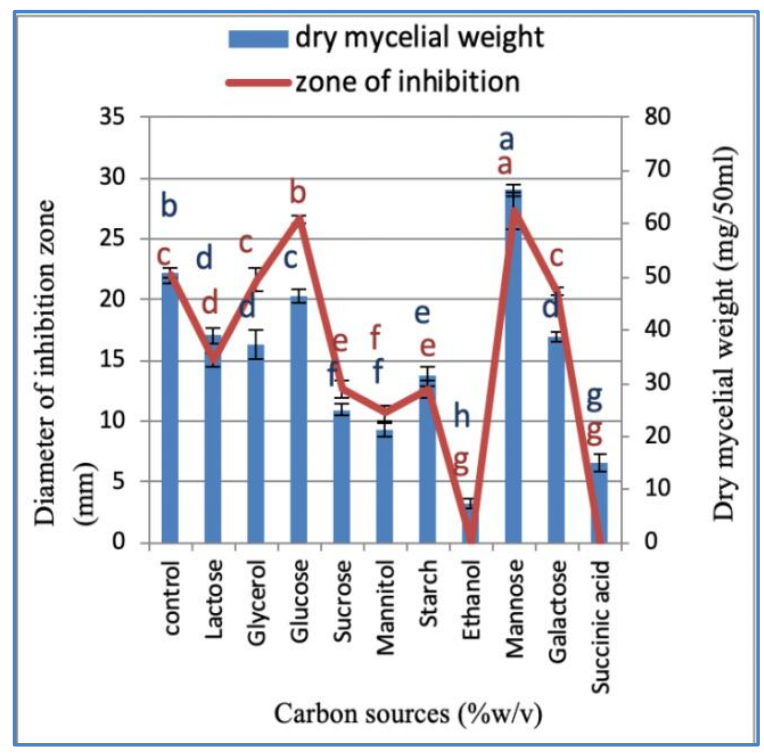

Fig 2: Effect of different carbon sources on growth and bioactive metabolite production by Amycolatopsis sp. ST-28. Vertical bars represent standard error ( \pm SE).

Means with different letters within an assay were significantly different ( $p$ value $<0.05$ ). The control used here is basal media. mum cell mass $(66.33 \pm 1.2 \mathrm{mg} / 50 \mathrm{ml})$ and inhibition zone $(27.33 \pm 1.45 \mathrm{~mm})$ against $S$. aureus. Further optimization of mannose concentration showed that mannose at a concentration of $1.5 \%(\mathrm{w} / \mathrm{v})$ was optimum for growth and bioactive metabolite production (Fig 3).

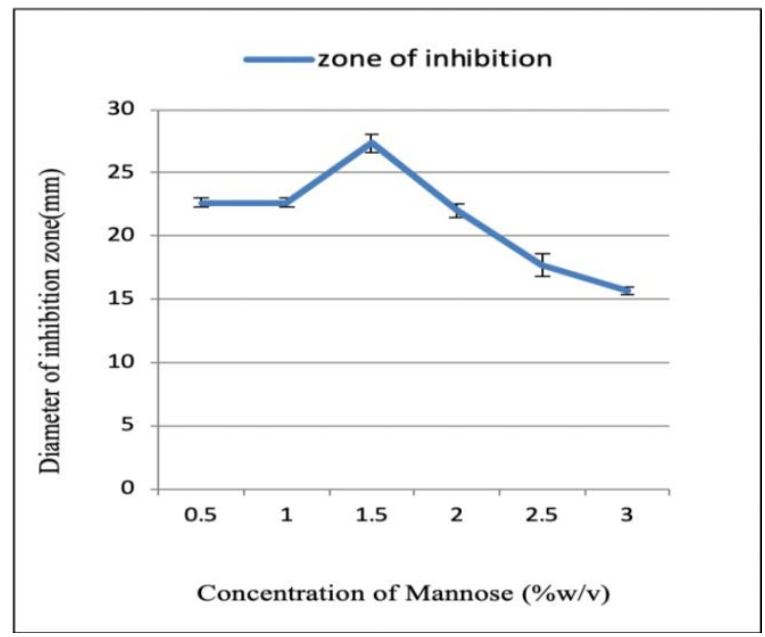

Fig 3: Effect of concentration of Mannose on bioactive metabolite production by Amycolatopsis sp. ST-28. Vertical bars represent standard error $( \pm \mathrm{SE})$.

The nitrogen sources demonstrated significant effect on growth and metabolism of Amycolatopsis sp. ST-28. Only few nitrogen sources were able to support the growth and bioactive metabolite production by the strain (Fig 4). Peptone as sole nitrogen source in the basal medium produced maximum mycelial growth $(66.66 \pm 1.20 \mathrm{mg} / 50 \mathrm{ml})$ and zone of inhibition $(27.66 \pm 1.20 \mathrm{~mm})$, followed by basal medium with beef extract and yeast extract. Some nitrogen sources such as $\mathrm{NaNO}_{3}, \mathrm{KNO}_{3}, \mathrm{NH}_{4} \mathrm{NO}_{3}$, $\mathrm{NH}_{4} \mathrm{Cl}$ and L-asparagine had inhibitory effect on bioactive metabolite production and growth of the strain. The optimum concentration for better growth and antimicrobial metabolite production was $0.8 \%(\mathrm{w} / \mathrm{v}$ ) peptone (Fig 5).

\section{Effect of temperature and pH}

The results showed that the most suitable temperature for growth and antimicrobial metabolite production of Amycolatopsis sp. ST-28 was in the range of $30-32 \pm 1^{\circ} \mathrm{C}$. Beyond this temperature, 
growth and metabolite production of the strain considerably decreased. Maximum mycelial yield $(67.33 \pm 0.88 \mathrm{mg} / 50 \mathrm{ml})$ and antimicrobial metabolite production $(27.33 \pm 0.33 \mathrm{~mm})$ were recorded at $32 \pm 1{ }^{\circ} \mathrm{C}$ (Fig 6). Thus Amycolatopsis sp. ST-28 has very narrow range of temperature for its growth and antimicrobial activity.

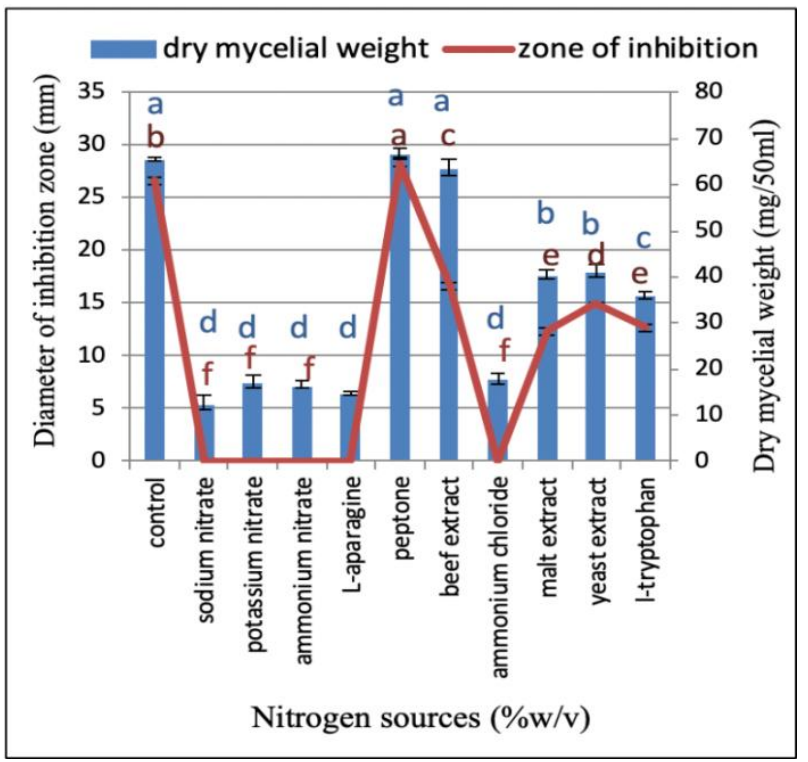

Fig 4: Effect of nitrogen sources on the growth and bioactive metabolite production by Amycolatopsis sp. ST-28. Vertical bars represent standard error $( \pm \mathrm{SE})$. Means with different letters within an assay were significantly different ( $p$-value $<0.05)$.). The control used here is basal media.

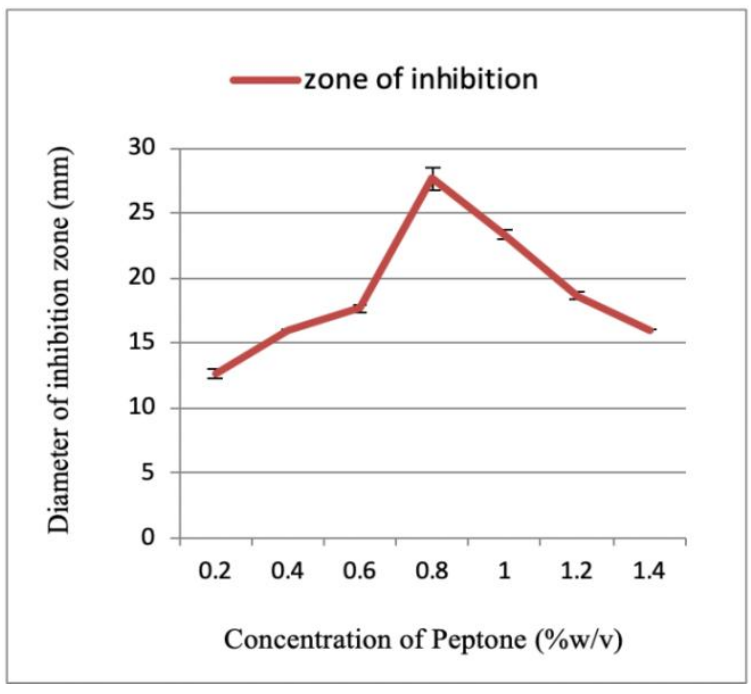

Fig 5: Effect of concentration of Peptone on bioactive metabolite production by Amycolatopsis sp. ST-28. Vertical bars represent standard error $( \pm \mathrm{SE})$
With regards to $\mathrm{pH}$, the experiment revealed that Amycolatopsis sp. ST-28 grew when the initial $\mathrm{pH}$ of the medium was adjusted to $\mathrm{pH} 5$ to 9 , and the biosynthesis of antimicrobial metabolite and growth were maximal at $\mathrm{pH} 6.5$ with $27.00 \pm 0.00 \mathrm{~mm}$ and $65 \pm 0.88 \mathrm{mg} / 50 \mathrm{ml}$ respectively. The growth and antimicrobial metabolite production decreased beyond pH 6.5 (Fig 7).

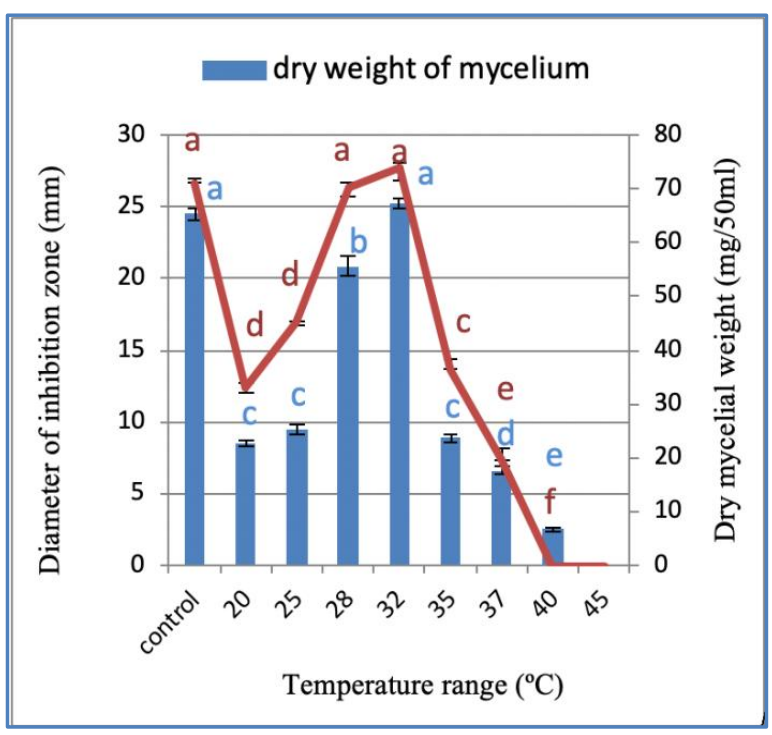

Fig 6: Effect of different temperature ranges on growth and bioactive metabolite production by Amycolatopsis sp. ST-28. Vertical bars represent standard error $( \pm \mathrm{SE})$. Means with different letters within an assay were significantly different $(p$-value $<0.05)$.). The control used here is basal media.

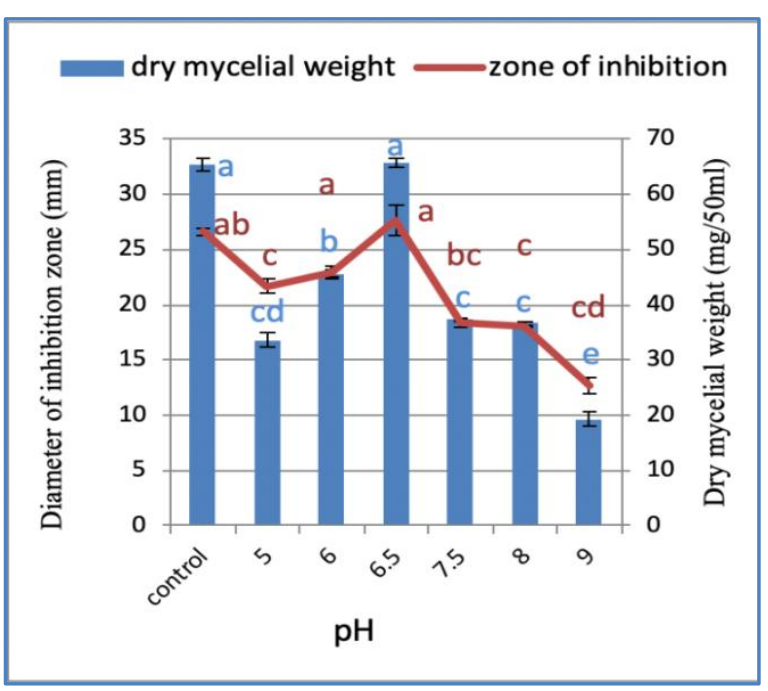

Fig 7: Effect of different $\mathrm{pH}$ ranges on growth and bioactive metabolite production by Amycolatopsis sp. ST-28. Vertical bars represent standard error $( \pm \mathrm{SE})$. Means with different letters within an assay were significantly different ( $p$-value $<0.05)$.). The control used here is basal media. 


\section{Effect of incubation period, agitation speed and inoculum volume}

The results showed that under good aeration, maximum growth and antimicrobial metabolite production were obtained. The optimum incubation time was 11 days under shaking condition. There was gradual decrease of antimicrobial activity and growth with

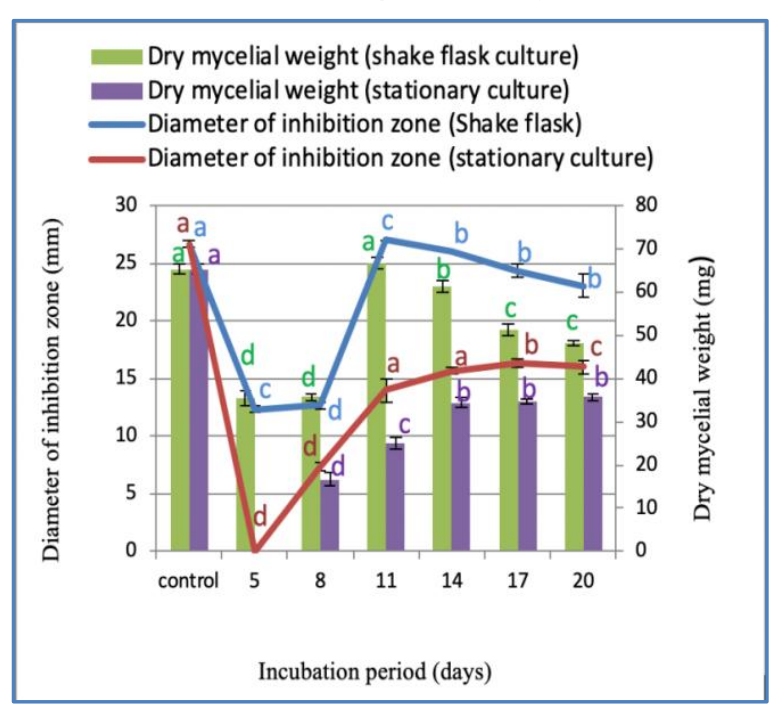

Fig 8: Effect of shaking and stationary condition on the growth and bioactive metabolite production Amycolatopsis sp. ST-28. Vertical bars represent standard error $( \pm S E)$. Means with different letters within an assay were significantly different $(p$-value $<0.05)$. The control used here is basal media further extension of incubation time (Fig 8). Inoculum dose of $11 \%(\mathrm{v} / \mathrm{v})$ concentration was most effective for maximum growth and yield of antimicrobial metabolite (Fig 9). Table 1 shows the detailed description of optimized culture conditions and nutritional requirements for maximum production of antimicrobial compounds.

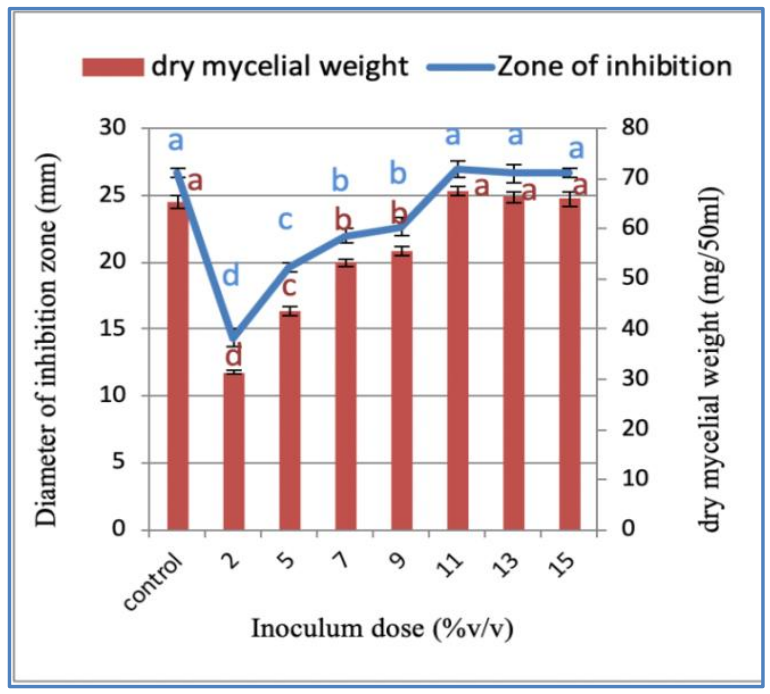

Fig 9: Effect of different levels of inoculums on growth and bioactive metabolite production by Amycolatopsis sp. ST28. Vertical bars represent standard error $( \pm S E)$. Means with different letters within an assay were significantly different $(p$-value $<0.05)$.). The control used here is basal media

Table 1: Optimized cultural parameters for the growth and antimetabolite production by rare actinobacterial isolate Amycolatopsis sp. ST-28

\begin{tabular}{cccc}
\hline Parameters & Optimum value & Dry mycelial weight $(\mathrm{mg} / 50 \mathrm{ml})$ & Zone of inhibition (mm) \\
\hline Carbon source & Mannose & $66.33 \pm 1.2$ & $27.33 \pm 1.45$ \\
Mannose concentration & $1.5 \%$ & - & $27.33 \pm 0.33$ \\
Nitrogen source & Peptone & $66.66 \pm 1.2$ & $27.66 \pm 1.2$ \\
Peptone concentration & $0.8 \%$ & - & $27.66 \pm 0.88$ \\
Temperature & $32^{\circ} \mathrm{C}$ & $67.33 \pm 0.88$ & $27.33 \pm 0.33$ \\
pH & 6.5 & $65.00 \pm 0.88$ & $27.66 \pm 1.3$ \\
Inoculum volume & $11 \% \mathrm{v} / \mathrm{v}$ & $67.66 \pm 0.88$ & $27.00 \pm 0.57$ \\
Incubation period & 11 days & $66.66 \pm 1.4$ & $27.00 \pm 00$ \\
Agitation & $150 \mathrm{rpm}$ & $66.66 \pm 1.4$ & $27.00 \pm 00$ \\
\hline
\end{tabular}




\section{Discussion:}

New drugs, especially antibiotics, are urgently needed to counter the threats of antibiotic resistant pathogens and to combat life threatening infectious diseases (34). The prevalence of methicillinresistant $S$. aureus in hospitals has increased from 3\% in the early 1980's to as high as $40 \%$ in recent times (35) and reports also suggest that coagulase negative $S$. aureus (CoNS) are becoming increasingly important in hospital settings where they cause serious infections (36). The focus, therefore, is on the rarer group of non-Streptomycetes actinobacteria, which are yet to be well exploited for their rich chemical diversity. These rare actinobacteria produce diverse and unique, unprecedented, sometimes very complicated compounds with excellent bioactive potency, and usually low toxicity $(37,38)$.

Attempts are also being made to study the secondary metabolism of these rare actinobacteria for their ability to produce bioactive metabolites such as antibiotics. Nutritional parameters and growth conditions exert strong influence in production of secondary metabolite by microbes (39). The medium constitution together with the metabolic capacity of the producing organisms greatly affects antibiotic biosynthesis (32). Therefore, this present investigation was conducted to determine the optimal cultural conditions such as nutritional, physical and chemical parameters for enhanced production of antimicrobial compounds by Amycolatopsis sp. ST-28.

The results of our study show that Amycolatopsis sp. ST-28, which is a rare actinobacterium, exhibited prominent antimicrobial activity against $S$. aureus. Previous reports have demonstrated antibiotic activity of Amycolatopsis balhimycina and Amycolatopsis orientalis against methicillin resistant $S$. aureus strains $(15,40)$. Therefore during the optimization experiment in our study, $S$. aureus was selected as the target organism for the antimicrobial assay. Amycolatopsis sp. ST-28 showed highest growth and antimicrobial metabolite production in Starch casein broth (SCB) as compared to the other tested media in our study. Similar findings were observed with Arthrobacter sp. SAA16 and Streptomyces afghaniensis VPTS3-1, when inoculated in different media, with SCB proving to be the best medium for growth and antimicrobial metabolite production in these studies $(39,41)$. This informed our selection of SCB as the basal medium (with or without C-sources) for the optimization studies.

Carbon sources are utilized by microorganisms for production of cell mass, primary and secondary metabolites and also for energy (42). Of the various carbon sources tested, basal medium supplemented with mannose at a concentration of $1.5 \%$ as sole carbon source supported the maximum growth as well antimicrobial metabolite production. Similar study on Streptomyces by Kreig and Holt reported that mannose was one of the most fermentable carbon sources by the actinobacteria for antibiotic production (43). However, further increase in the concentration of mannose did not increase the antimicrobial metabolite production in our study. This is probably because higher concentration of carbon tends to cause carbon repression which interferes with secondary metabolite formation (44). Similarly, other researchers have reported that Amycolatopsis mediterranei utilized glucose $(1 \%)$ for rifamycin production however increase in concentration of glucose did not increase rifamycin production, which is attributable also to carbon catabolite repression (45). Nitrogen plays an important role in biosynthesis of secondary metabolites. Nitrogen sources are classified into two types; inorganic nitrogen source which are regarded as the fast metabolizable nitrogen sources, wherein long-time accumulation of product does not occur, and the organic nitrogen sources are sustainable sources that are beneficial for steady accumulation of product (46). In the present study, organic nitrogen sources showed relatively higher 
antimicrobial metabolite production and growth as compared to inorganic nitrogen sources. Peptone, an organic nitrogen source at a concentration of $0.8 \%(\mathrm{w} / \mathrm{v})$ in the basal medium was found optimum for the growth and antimicrobial metabolite production. The results agree with the earlier studies which suggest that low concentration of peptone $(1 \%)$ greatly favored antimicrobial metabolite yield (32). The inorganic nitrogen sources such as ammonium nitrate and ammonium chloride supported growth to certain extent but did not allow production of antimicrobial metabolite. This might be due to presence of ammonium which inhibits the biosynthesis of antibiotics by decreasing the activities of enzymes involved in nitrogen metabolism (47). This is similar to the findings of the work done by Yu et al., (48).

Physiological factors such as $\mathrm{pH}$ and temperature have profound effects on the microbial growth and antimicrobial metabolite production. The results of our study indicated that growth and antimicrobial activity increased with gradual increase of $\mathrm{pH}$ from 5 to optimum $\mathrm{pH}$ of 6.5 , and thereafter decrease in antimicrobial metabolite production and growth occurred. Actinobacteria have the ability to tolerate wide range of temperature. Temperature of $32 \pm 1^{\circ} \mathrm{C}$ was found optimal for growth as well antimicrobial metabolite production in our study, thus, confirming the organism as a strict mesophile. Similar studies conducted by other researchers have also confirmed $\mathrm{pH}$ and temperature as critical factors for growth and metabolism of actinobacteria $(25,41,45,49)$.

The variations in inoculum dose were also observed to have significant influence on growth and bioactive metabolite production in our study, with $11 \%(\mathrm{v} / \mathrm{v})$ inoculum found optimum for antimicrobial metabolite production when tested in the range of 2 to $15 \%$. Other researchers have demonstrated inoculum volume effects on bioactive metabolite production, with lower levels of inoculum resulting in insufficient biomass leading to reduced product formation, while higher level of inoculum may produce too much biomass leading to poor product formation $(26,48,50)$.

The influence of incubation period and agitation has also been studied, as this forms an integral part of optimization. Krishna et al., observed that a period of 11 days and aeration of $50 / 250 \mathrm{ml}$ was optimum for the production of rifamycin by Amycolatopsis mediterranei (45) while Thakur et al., observed that Streptomyces sp. 201 required a maximum period of 6 days under shaking conditions for optimum antibiotic yield and biomass production (25). In the present study, maximum incubation period required for optimum growth and antibiotic yield was 11 days under shaking conditions, but under stationary condition, the growth and antimicrobial metabolite production were comparatively slower and the optimum production of antibiotics was on the day 17. Thus, agitation which provides proper oxygen transfer to the cells generally caused increase in growth of the organism.

\section{Conclusion:}

Our study reveals that a rare actinobacteria strain, Amycolatopsis sp. ST-28 isolated from tea garden soil produced maximum growth and bioactive metabolite with a medium supplemented with $1.5 \%$ mannose as carbon source, peptone at a concentration of $0.8 \%$ as nitrogen source, and other process parameters such as media $\mathrm{pH}$ of 6.5, incubation temperature of $32 \pm 1{ }^{\circ} \mathrm{C}$, inoculum volume of $11 \%(\mathrm{v} / \mathrm{v})$ and incubation period of 11 days under shaking condition. Therefore, crude extracts of Amycolatopsis sp. ST-28 has huge potential to be explored as antimicrobial agents for future development. Further characterization, purification and elucidation of the antimicrobial compounds present in the crude extracts are parts of an ongoing research.

\section{Acknowledgments:}

The first author acknowledges the UGC, New Delhi and Ministry of Minority 
Affairs, India for financial support in form of Maulana Azad National Fellowship (MANF) and the Head, Department of Botany, Gauhati University, for providing facilities under SAP and FIST program, to carry out this research work.

\section{References:}

1. Demain, A. L. Microbial Biotechnology. Trends Biotechnol. 2000; 18:26-31

2. Berdy, J., Kadar-Pauncz, J., MehesfalviVajna, Z., Horvath, G., and Gyimesi, J. Metabolites of gentamicin producing Micromonospora species. Part 1. Isolation and identification of metabolites. J Antibiot. 1977; 30: 945-953

3. Lam, K. S., Mattei, J., and Forenza, S. Carbon catabolite regulation of rebeccamycin production in Saccharothrix aerocolonigenes, $\mathrm{J}$ of Industr Microbiol. 1989; 4 (2): 105-108 4.

Selvin, J., Shanmughapriya, S., Gandhimathi, R., Seghal, G. R., Rajeeth, R. T., Natarajaseenivasan, K., and Hema, T.A. Optimization and production of novel antimicrobial agents from sponge associated Nocardiopsis dassonvillei MAD08. Appl Microbiol Biotechnol. 2009; doi: 10.1007/s 00253-009-1878

5. Sathiyayanarayanan, G., Gandhimathi, R., Sabarathan, B., Seghal Kiran, G., and Selvin, J. Optimization and production of pyrrolidone antimicrobial agent from marine sponge-associated Streptomyces sp. MAPS15. Bioprocess and Biosystems Engineering. 2014; doi: 10-1007/S00449013-1023-2

6. Bhattacharyya, P. N., and Jha, D. K. Optimization of cultural conditions effecting growth and improved bioactive metabolite production by subsurface Aspergillus strain. TSF 146. Int J Appl Biol Pharm Technol. 2011; 2 (4): 133-143

7. Brahmachari, G. Bioactive Natural Products: Opportunities and Challenges in Medicinal Chemistry, World Scientific Publishing Co. Pte Ltd: Singapore, 2012.

8. Fidalgo, S., Vazquez, F., Mendoza, M. C., Perez, F., and Mendez, F. J. Bacteraemia due to Staphylococcus epidermidis: microbiologic, epidemiologic, clinical, and prognostic features. Rev Infect Dis. 1990; 12: $520-528$

9. Roberts, F. J., Geere, I. W., and Coldman, A. A three-year study of positive blood cultures, with emphasis on prognosis. Rev Infect Dis. $1991 ; 13: 34-46$

10. Lowry, F. D. Staphylococcus aureus. N Engl J Med. 1998; 339: 520-535

11. Tiwari, K., and Gupta, R. K. Rare actinomycetes: a potential storehouse for novel antibiotics. Crit Rev Biotechnol.
2012; 32 (2): 108-132

12. Lechevalier, M. P., Prauser, H., Labeda, D. P., and Ruan, J. S. Two new genera of nocardioform actinomycetes: Amycolatagen. nov. and Amycolatopsis gen. nov. Int J Syst Bacteriol. 1986; 36: 29-37

13. Embley, T. M., Smida, J., and Stackebrant, $\mathrm{E}$. The phylogeny of mycolate-less wall chemotype IV actinomycetes and description of Pseudonocardiaceae fam. nov. Syst Appl Microbiol. 1988; 11:44-52 Warwick, S., Bowen, T., Meveigh, H., and Embley, T. M. A phylogenetic analysis of family Pseudonocardiaceae and genus Actinokineospora and Saccharothrix with $16 S$ rRNA sequences and a proposal to combine the genera Amycolata and Pseudonocardia in an emended genus Pseudonocardia. Int J Syst Bacteriol. 1994; 44: 293-299

15. Nadkarni, S. R., Patel, M. V., Chaterjee, S., Vijaykumar, E. K., Derikan, K. R., Blumbach, J., Ganguli, B. N., and Limber, M. Balhimycin, a new glycopeptides antibiotic produced by Amycolatopsis sp. Y86, 21022. Taxonomy, production, isolation and biological activity. J Antibiot. 1994; 47: 334-341

16. Ueno, M., Iijima, M., Masuda, T., Kinoshita, N., Linuma, H., Naganawa, H., Hamada, M., Ishizuka, M., and Takeuchi, T. Dethymycin, a novel immunosuppressant isolated from Amycolatopsis. J Antibiot. 1992; 45: 18191826

17. Sensi, P., Greco, A. M., and Ballotta, R. Rifomycin. I. Isolation and properties of rifomycin B and rifamycin complex. Antibiot Annu. 1959; 7: 262-270

18. Barna, J. C., and Williams, D. H. The structure and mode of glycopeptides antibiotics of the vancomycin group Annu. Rev Microbiol. 1984; 23: 15-24

19. Myers, N. Threatened biotas: "hot spots" in tropical forests. Environmentalist.1988; 8: 187-208

20. Hayakawa, M. Studies of isolation and distribution of rare actinomycetes in soil. Actinomycetologica. 2008; 22:12-19

21. Yamamamura, H., and Hayakawa, M. Application of Sucrose-gradient centrifugation for selective isolation of Nocardia sp. from soil. J Appl Microbiol. 2003; 95(4): 677-685

22. Shirling, E. B., and Gottlieb, D. Methods for characterization of Streptomyces sp. Int J Syst Bacteriol. 1966; 16: 313-340

23. Waksman, S. A. The Actinomycetes Classification and identification and description of genera and species, 2. Baltimore: Williams and Wilkins Company. $1961 ; 327$

24. Alam, M., and Jha, D. K. Antimicrobial property of Amycolatopsis sp. isolated from tea garden soil (unpublished). 09-11-2016

25. Thakur, D., Bora, T. C., Bordoloi, G. N., and Mazumdar, S. Influence of nutrition and 
culturing conditions for optimum growth and antimicrobial metabolite production by Streptomyces sp. 201. J de Mycologie Medicale. 2009; 19: 161-167

26. Dasari, V. R. R. K., Yugandhar, N. M., and Donthireddy, S. R. R. Screening of antagonistic marine actinomycetes: optimization of process parameters for production of novel Antibiotic by Amycolatopsis alba var. nov. DVR D4. J Microbial Biochem Technol. 2011; 3:5

27. Seong, C. N., Choi, J. H., and Baik, K. S. An improved selective isolation of rare Actinomycetes from forest soil. J Microbiol. 2001; 39 (1): 17-23

28. Nayera, A. M., Abdelwahed N, A., Abdallah, D E., EI-Ghawas S. M., and Badr EL-Din Ahmed I. E. Isolation, identification and optimization of antimicrobial metabolites produced by soil derived actinomycetes. The Egyptian J Exper Biol (Botany). 2012; 8 (2): 205-217

29. Pridham, T. G., Anderson, P., Foley, C., Lindenfelser, L. A., Hesseltine, C. W., and Benedict, R. G. A selection of media for maintenance and taxonomic study of Streptomycetes. Antibiotics Ann. 1: 947953

30. Pridham, T. G., and Gottlieb, D. The utilization of carbon compounds by some Actinomycetales as an aid for species determination. J Bacteriol. 1948; 56: 107114

31. Grove and Randall. Assay Methods of Antibiotics: A Laboratory manual [Antibiotic Monographs] New York. Medical Encyclopedia. 1955; 80

32. Gopi R, N., Ramakrishna, D. P. N., and Rajagopal, S. V. Optimization of Culture conditions of Streptomyces rocheii (MTCC 10109) for production of antimicrobial metabolite. Egyptian J Biol. 2011; 13: 2129

33. Suetsuna, K., and Osajima, Y. Cultural conditions for production of griseorhodin by a culture of Streptomyces californicus JCM 6910. Suisan Diagakkakenkyn Hokoku. 1990; 38: 17-22

34. Manivsagar, P., Venkatesan, J., Sivakumar, K., and Kim, S. K. Pharmaceutically active secondary metabolites of Marine actinobacteria. Microbiol Res. 2014; 169: 262-278

35. Nurettin, S., and Aysel, U. Investigation of Antimicrobial activity of some Streptomyces isolates. Turk J Biol. 2003; 27: 79-84

36. Kloos, W. E., and Bannermann, T. L. Update on the clinical significance of coagulase negative Staphylococcus. J Clin Microbiol. 1994; 33:1060-1063

37. Berdy, J. Bioactive microbial metabolites. J Antibiot. 2005; 58 (1): 1-26

38. Kurtboke, D. Bio-discovery from rare actinomycetes: an eco-taxonomical perspective. Appl Microbiol Biotechnol. 2012; 93: 1843-1852
39. Satapathy, S., and Mohapatra, S. B. Optimization of cultural parameters for enhanced production of Antimicrobial Bioactive metabolite by Arthrobacter $s p$. SAS16. Indian J Sci Technol. 2017; 10: 38

40. Pittenger, R. C., and Brigham, R. B. Streptomyces orientalis sp., the source of vancomycin. Antibiot Chemother. 1956; 6: 642-6647

41. Vijaykumar, R., Panneerselvam, K., Muthukumar, C., Thajuddin, N., Panneerselvam, A., and Saravanamuthu, R. Optimization of Antimicrobial Production by a Marine Actinomycete Streptomyces afghaniensis VPTS3-1 Isolated from Palk Strait, East Coast of India. Indian J Microbiol. 2012; 52 (2): 230-239

42. Padma, P. N., Rao, A. B., and Reddy, G. "Effective screening of carbon and nitrogen substrates by Placket-Burman design for production of Vancomycin by Amycolatopsis orientalis" Asian J Biochem Pharm Res. 2014; 3 (4): 200-208

43. Kreig, N. R., and Holt, J. G. Bergey's Manual of Determinative Bacteriology. Baltimore/London: Williams and Wilkins. Vol 4, 1989; 2451-2458

44. Ruiz, B. I., Chávez, A., Forero, A, et al. Production of microbial secondary metabolites: Regulation by Carbon source. Crit Rev Microbiol. 2010; 36 (2):146-167

45. Krishna, P. S. M., Venkateswarlu, G., and Rao, L. V. Studies on fermentative production of rifamycin using Amycolatopsis mediterranei. World J Microbiol Biotechnol. 1998; 14: 689-691.

46. Radhakrishnan, M., Gopikrishnan, V., Balagurunathan R., and Vanaja, K. Effects of critical medium components and culture conditions on anti-tubercular pigment production from novel Streptomyces sp. D25 isolated from Thar Desert, Rajasthan. J Appl Pharm Sci. 2015; 5 (06): 015-019 47. Bascaran, V., Hardisson, C., and Brana, A. F. Regulation of Nitrogen Catabolic enzymes in Streptomyces clavuligerus. J Gen Microbiol. 1989; 135 (9): 2465-2474

48. Yu, J., Liu, Q., Sun, Q., Yan, J., Qi, X., and Fan, S. Effect of liquid culture requirements on antifungal antibiotic production by Streptomyces rimosus MY02. Bioresource T. 2008; 99 (6): 2087-2091

49. Subathra, D. C., Anuj, S., Shubham, R., Jemimah, N., and Mohana, S. V. Strain improvement of optimization studies for enhanced production of erythromycin in bagasse based medium using Saccharopolyspora erythraea3. Biotechnol. 2015; 5 (1): 23-31

50. Mudgetti, R. E. Manual of industrial biotechnology. American Society for Microbiology, Washington DC.1986 